\title{
TRANSMISSÃO MATERNO -INFANTIL DO VÍRUS DA IMUNODEFICIÊNCIA HUMANA: AVALIAÇÃO DE MEDIDAS DE CONTROLE NO MUNICÍPIO DE SANTOS
}

\author{
Teresa Maria Isaac Nishimoto*, José Eluf Neto, Mauro Abrahäo Rozman \\ Trabalho realizado no Departamento de Medicina Preventiva da Faculdade de \\ Medicina da Universidade de São Paulo, São Paulo, SP
}

RESUMO - OBjetivos. Estimar O risco da transmissão materno. infantil (TMI) do HIV no município de Santos e avaliar o efeito da introduçáo de medidas preventivas na transmissão vertical do HIV, tais como: utilização de AZT pela gestante, durante 0 pré-natal, trabalho de parto e parto, uso de AZT pelo recém-nascido; substituiçăo do aleitamento natural pelo artificial e indicacáa de cesárea.

Métodos. Trata-se de um estudo de coorte. Os dados foram coletados dos prontuários das gestantes e das crianças nos serviços de referência para 0 atendimento de pessoas vivendo com HIV/Aids. Para estimar o risco de transmissão materno. infantil do HIV, dividiu-se 0 número de mães cujos filhos adquiriram 0 vírus por transmissão vertical pelo número de mães incluídas no estudo. Para estimar o risco de TMI associado aos fatores investigados, calcularam-se os riscos relativos com intervalos de confiança de $95 \%$ (IC 95\%), considerando a ocorrência de transmissão como variável dependente e os outros fatores (idade materna, realização de pré-natal, uso de AZT oral, uso de AZT xarope, idade gestacional e amamentação) como variáveis independentes. Para controlar
- possivel efeito confundidor de algumas variáveis, foi realizada análise estratificada pela técnica de Mantel-Haenszel.

Resultados. A ocorrência da TMI do HIV foi estabelecida em 144 crianças. Quatorze delas foram classificadas como infectadas; 0 risco de transmissão foi de 0,097 (IC 95\%; 0,030-0,163). 0 risco de transmissão foi menor nas mulheres com menos de 30 anos de idade. $\mathrm{Na}$ análise univariada, 0 risco de transmissão materno. infantil do HIV esteve associado de modo estatisticamente significante com: idade materna, realização do pré-natal, uso de AZT oral, uso de AZT xarope, idade gestacional (Capurro) e amamentação.

Conclusaio. 0 presente trabalho mostrou que a implantaçäo de medidas preventivas tem importância na prevenção da transmissão do HIV mäe-filho, com redução de quase $40 \%$ no risco desta transmissão comparada à encontrada anteriormente sem a utiliza. ção de medidas preventivas.

UnITERMOS: Transmissão materno-infantil ou vertical. HIV. Síndrome de imunodeficiência adquirida. Fatores de risco. Medidas de proteção.

\section{INTRODUÇÃO}

A transmissão materno-infantil do HIV é uma via de exposição de múltiplas causas e a influência dos fatores associados com a transmissão do vírus varia com as populações estudadas'. A transmissão vertical do HIV pode ocorrer no período intra-útero, intraparto e após o parto através do aleitamento materno². A maioria dos casos de transmissão vertical do HIV ocorre durante o trabalho de parto e durante o parto (60\%-65\%) e o restante da transmissão (35\%-40\%) no período intra-útero, principalmente nas últimas semanas de gestação, em estudos realizados em locais onde as mães não amamentaram seus bebês. Vários fatores estão associados à transmissão materno-infantil do HIV, entre eles destacam-se

* Correspondência

Av. Presidente Wilson, 16 - apto. 111

CEP 11065-200 - Santos - São Paulo mmitoiti@atribuna.com.br a viremia materna elevada, a doença materna avançada, tipo de parto, aleitamento materno, corioamnionites, ruptura prematura da placenta, prematuridade e tabagismo ${ }^{3-12}$.

As evidências apontam como principal fator contribuinte para a redução da transmissão vertical do HIV a promoção de intervenções que reduzam a carga viral materna. Uma dessas intervenções foi a aplicação do protocolo 076 do Aids Clinical Trial Group, estudo clínico publicado em 1994, no qual se demonstrou que a administração da Zidovudina para a mulher infectada durante a gestação, parto e para o recém-nascido nas primeiras semanas de vida reduzia a transmissão materno-infantil do HIV em 67,5\% ${ }^{13}$. Outros estudos comprovaram a eficácia das intervenções com anti-retrovirais, mesmo que usados tardiamente $14,15,16$

No Brasil, após a publicação dos resultados do protocolo 076 e considerando o aumento no número de casos de HIV/Aids nas mulheres, observado no período entre 1984-
$2002^{17}$, notou-se o progressivo aumento no número de crianças infectadas pela transmissão da mãe para o filho, tornando-se a principal categoria de exposição entre as crianças menores de 13 anos.

Frente a estas duas evidências, a prevenção da transmissão vertical do HIV foi então estabelecida pelo Ministério da Saúde como uma das prioridades do Programa Nacional de DST e Aids e pelo Programa de DST/Aids do Estado de São Paulo e do município de Santos ${ }^{18}$.

Em Santos, várias ações foram planejadas para modificar este cenário epidemiológico: criação do centro de referência às crianças HIV soropositivas em outubro de 1994 e às gestantes soropositivas para o HIV em janeiro de 1997; treinamento das equipes multidisciplinares; aquisição de material informativo sobre prevenção da transmissão vertical do HIV e abastecimento de Zidovudina (AZT) nas três apresentações (oral, injetável e xarope). 
O objetivo deste trabalho foi estimar o risco de transmissão no município no período do estudo, avaliar as principais variáveis relacionadas à transmissão do vírus e avaliar o efeito da introdução de medidas preventivas na transmissão vertical do HIV no município.

\section{MÉTOdOS}

Foi conduzido um estudo de coorte no município de Santos entre I de março de 1997 a 29 de fevereiro de 2000.

Foram consideradas elegíveis as mulheres com diagnóstico de Aids ou soropositivas para - HIV que deram à luz bebês vivos. Foram incluídas mulheres com diagnóstico de Aids ou sorologia anti-HIV positiva confirmados antes da gravidez, no pré-natal ou na maternidade. Essas mulheres foram recrutadas: no ambulatório do Centro de Referência em Aids (local de referência da cidade para acompanhamento e tratamento de pessoas soropositivas para o HIV); nas 19 unidades básicas de saúde com serviço de pré-natal; e nas duas maternidades públicas da cidade, Hospital e Maternidade Silvério Fontes, da Secretaria Municipal de Saúde, e Hospital Guilherme Álvaro, da Secretaria Estadual de Saúde. Após o nascimento, as crianças, filhas das gestantes inclusas no estudo, eram encaminhadas para o Núcleo Integrado da Criança, da Secretaria Municipal de Saúde, para atendimento mensal especializado. As crianças foram acompanhadas por dois anos, sendo dispensadas a partir de então em caso de negativação da sorologia para o HIV; as crianças infectadas permaneceram no serviço para seguimento e tratamento.

As gestantes foram consideradas infectadas pelo HIV quando o resultado era positivo em pelo menos dois tipos diferentes de testes sorológicos comercialmente disponíveis na época. Realizaram-se os testes em uma ou mais amostras de sangue da mãe, ou em uma amostra da mãe e outra da criança, até junho de 1998. A partir da publicação da portaria 488, em 18 de junho de 1998 no Diário Oficial da União, foram consideradas infectadas pelo HIV as mulheres que realizaram dois ou mais testes com técnicas laboratoriais diferentes, com resultado reagente em pelo menos duas amostras de sangue.

A criança foi considerada infectada quando apresentou resultado positivo em duas amostras de sangue, com as quais se realizaram testes sorológicos de triagem com princípios metodológicos e/ou antígenos diferentes, e um teste confirmatório positivo aos 18 meses ou mais de idade; ou quando realizou teste de detecção de RNA viral entre o primeiro e 0 sexto mês de vida com resultado de carga viral detectável; ou quando apresentou sinais e sintomas da Aids infantil em qualquer idade ${ }^{19}$.

A criança não foi considerada infectada quando o teste de detecção de RNA viral foi negativo em duas amostras obtidas entre um e seis meses, sendo uma delas obrigatoriamente após o quarto mês de vida; ou quando, em crianças com mais de seis meses, duas amostras foram negativas em testes de deteç̧ão para anticorpos anti-HIV. Os critérios para exclusão da infecçãa aplicaram-se às crianças que não estivessem sendo amamentadas. Como a amamentação é considerada nova exposição ao HIV, a criança amamentada foi submetida novamente a testes para diagnóstico da infecção pelo HIV ${ }^{19}$.

Em nove crianças não foi possível determinar o status da infecção por HIV. As mães dessas crianças foram excluídas da análise. Em gravidezes múltiplas incluiu-se apenas um dos gemelares (após sorteio) na avaliação da ocorrência de transmissão materno-infantil. Nos casos em que as mulheres tiveram mais de um filho (não gemelares), no período do estudo, somente uma das gestações foi incluída, por sorteio.

\section{Coleta de informações}

As informações foram obtidas por meio de consulta aos prontuários das gestantes nos serviços listados anteriormente e aos prontuários das crianças no serviço municipal de referência para atendimento de crianças filhas de mães soropositivas para o HIV. Registraram-se as informações relativas aos fatores de interesse em uma ficha elaborada especificamente para o estudo.

As informações registradas incluíam: dados sociodemográficos; dados do pré-natal; categoria de exposição materna ao HIV; condiç̧ão clínica e imunológica materna; uso de AZT pela mãe (na gravidez ou parto); tempo de ruptura de bolsa; tipo de parto; idade gestacional pelo método de Capurro (avaliação pelo exame clínico e neurológico do recém-nascido nas primeiras seis horas de vida); peso do recém-nato ao nascimento; uso de AZT xarope pelo bebê (nas primeiras 24 horas de vida); aleitamento materno.

\section{Análise estatística}

Para estimar o risco de transmissão materno-infantil do HIV (com intervalo de 95\% de confiança), dividiu-se o número de mães cujos filhos adquiriram o vírus por transmissão vertical pelo número de mães incluídas no estudo.

Inicialmente foi realizada uma análise descritiva segundo as principais variáveis investigadas. Para estimar o risco de transmissão vertical associado aos fatores investigados, calcularam-se riscos relativos com intervalos de 95\% (IC 95\%) de confiança, considerando a ocorrência de transmissão como variável dependente e os outros fatores como variáveis independentes. Estas variáveis foram agrupadas em duas categorias.

Análise de variância foi empregada na comparação de algumas variáveis como: idade e escolaridade (em número de anos de estudo) maternas, peso do recém-nato e idade gestacional. Nesses casos, a significância da diferença entre as variâncias foi avaliada por meio do teste de Bartlett ${ }^{20}$; quando significante, foi utilizado teste não paramétrico

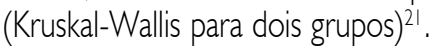

Para controlar o possível efeito confundidor de algumas variáveis, foi realizada análise estratificada pela técnica de Mantel-Haensze ${ }^{22}$. Nesta análise, foram incluídas as variáveis que se associaram significativamente à transmissão $(p<0,05)$ na análise univariada. Devido ao número limitado de pares mulheres/filhos ( I44) em que ocorreu transmissão vertical, procedeu-se à estratificação por apenas uma variável de cada vez.

Foram calculados os riscos de transmissão vertical de HIV segundo a data de nascimento da criança, agrupadas em três categorias: $1^{\circ}$ de março de 1997 a 28 de fevereiro de $1998,1^{\circ}$ de março de 1998 a 28 de fevereiro de $1999 \mathrm{e}^{\circ}$ de março de 1999 a 29 de fevereiro de 2000. Para avaliar a significância estatística, foi usado o teste do Qui-quadrado de tendência linear ${ }^{21}$.

\section{Consideraçōes éticas}

O estudo foi aprovado pelos comitês de ética dos dois hospitais, pelos diretores das unidades básicas de saúde participantes desta investigação e pela Comissão de Ética em Pesquisa do Hospital das Clínicas da Faculdade de Medicina da Universidade de São Paulo (protocolo de pesquisa n 605/99). 


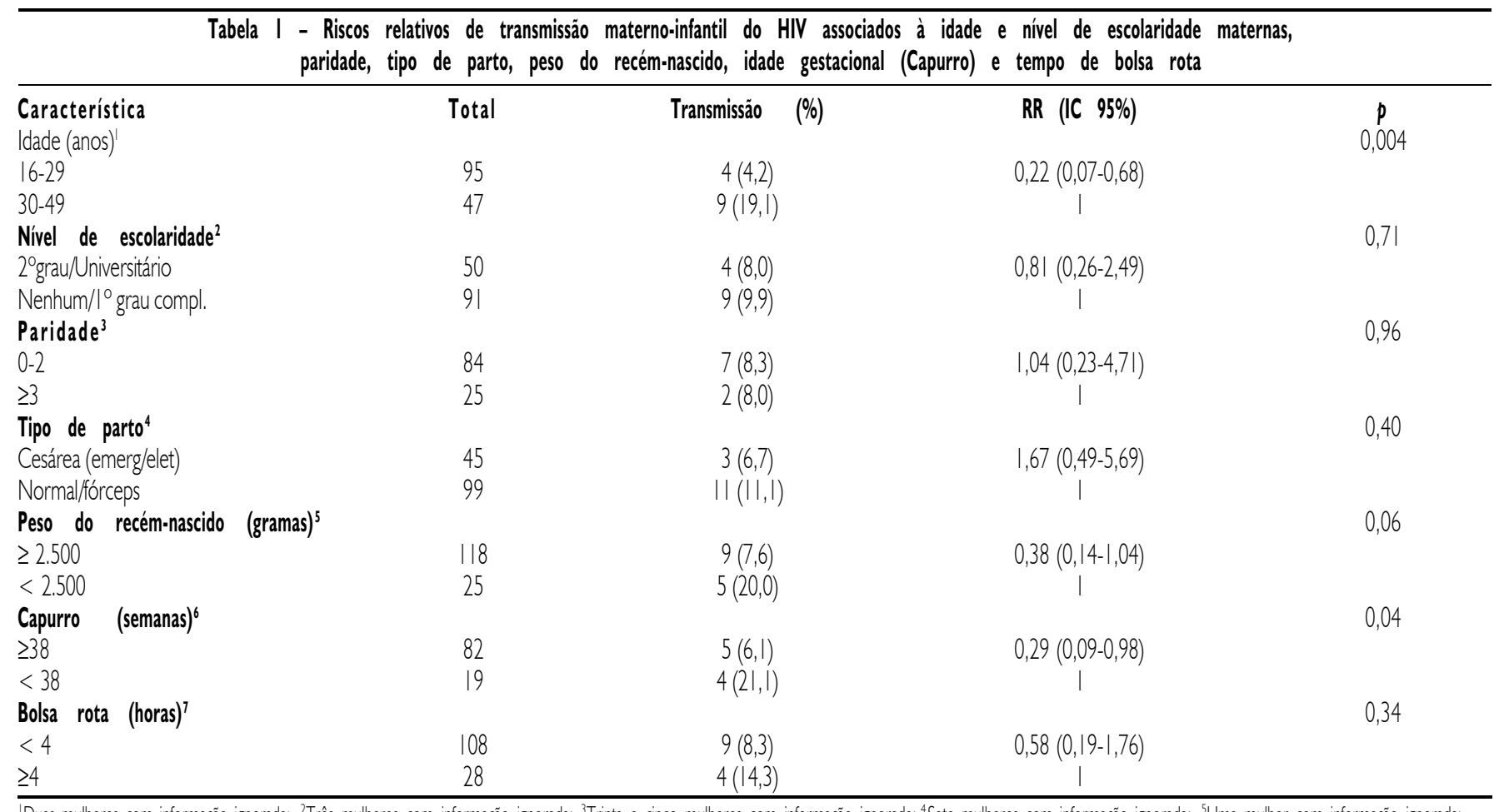

'Duas mulheres com informação ignorada; ${ }^{2}$ rês mulheres com informação ignorada; ${ }^{3}$ Trinta e cinco mulheres com informação ignorada; ${ }^{4}$ Sete mulheres com informação ignorada; ${ }^{5}$ Uma mulher com informação ignorada; ${ }^{6}$ Trinta e seis mulheres com informação ignorada; 7 Oito mulheres com informação ignorada

\section{Resultados}

De $1^{\circ}$ de março de 1997 a 29 de fevereiro de 2000, foram identificadas 160 gestações de mulheres infectadas por HIV que resultaram no nascimento de 163 filhos vivos. Em três mulheres com gestação múltipla não se observou discordância quanto à ocorrência de transmissão vertical do HIV entre os gêmeos: um par de gêmeas infectadas, e dois pares de gêmeos não infectados.

Foram incluídas nas análises, através de sorteio, uma criança dos três partos gemelares e uma criança, quando a mãe teve mais de uma gestação. Foram retiradas das análises crianças nas quais não se pode verificar a situação final da infecção pelo HIV. A ocorrência ou não da transmissão do HIV foi estabelecida nas $\mid 44$ restantes. Exceto quando explicitado, os resultados apresentados a seguir são referentes às I44 mulheres/crianças em que foi possível confirmar ou afastar a ocorrência de transmissão materno-infantil (com base nos critérios relatados anteriormente).

Quatorze crianças foram classificadas como infectadas; o risco de transmissão foi, portanto, de 0,097 (IC 95\% 0,030 - 0, I63). A idade mínima das mulheres foi 16 anos e a máxima 42, com média de 27,3 anos [desvio padrão $=5, \mid$ anos] e mediana de 27 anos. O nível de escolaridade das mulheres foi baixo: a maioria (77,3\%) não ultrapassava o ensino fundamental (antigo $\mathrm{I}^{\circ} \mathrm{grau}$ ). Quanto à renda familiar per capita, a média foi 2.5 salários-mínimos, quase um terço (29\%) vivia no máximo com um salário per capita ao mês.

A categoria de exposição materna ao HIV mais freqüente foi a sexual I I I (77,6\%). Não se pesquisou quantas seriam parceiras de usuários de drogas injetáveis, porém a categoria de exposição sexual mais uso de droga injetável foi 27 (18,9\%). Em uma mulher $(0,7 \%)$ houve contaminação por transfusão de sangue.

Ao avaliar a presença de sintomas de Aids em mulheres, 106 (98, 1\%) estavam assintomáticas e 2(1,9\%) sintomáticas, as restantes não tinham sido avaliadas pelo serviço de Aids. Em relação a linfócitos $\mathrm{TCD}_{4}+$ e carga viral, $50 \%$ do total correspondiam à categoria "ignorados" ou sem informação, praticamente impedindo a análise da condição imunológica materna que se pretendia fazer no presente estudo.

Cento e treze mulheres $(79,6 \%)$ fizeram pré-natal. A sorologia para pesquisa da infecção pelo HIV no pré-natal foi realizada em 7I $(51,8 \%)$ das gestantes. As outras mulheres não realizaram o teste anti-HIV por duas razões diferentes: 40 (29,0\%) já haviam feito a sorologia anteriormente à gravidez e já estavam matriculadas no serviço de referência de Aids e a $26(19,2 \%)$ o teste não foi oferecido ou foi oferecido, mas a gestante não o realizou.

Em II 8 casos (82,5\%) as crianças nasceram com peso adequado e 86 mulheres (79,7\%) deram à luz crianças a termo, ou seja, com mais de 38 semanas. O peso médio ao nascer foi de 2933 gramas (IC 95\% 28313052) e a idade gestacional média foi 38 semanas e I/7 dias (IC 95\% 37,6-38,4).

Em 120 recém-nascidos (85,7\%) foi prescrito AZT xarope nas primeiras $24 \mathrm{~h}$ de vida e 15 deles foram amamentados pela mãe, apesar da mãe ter sido orientada para não amamentar.

Realizou-se uma comparação entre as médias dos pesos e as médias das idades gestacionais (calculadas com base na data da última menstruação, DUM) dos recém-nascidos nos grupos com e sem transmissão. 0 peso médio dos RN em que não houve transmissão (299| gramas) foi maior que o peso médio dos RN em que houve transmissão $(2547 \mathrm{~g})$, sendo esta diferença estatisticamente significante $(p=0,02)$. Entre as médias das 


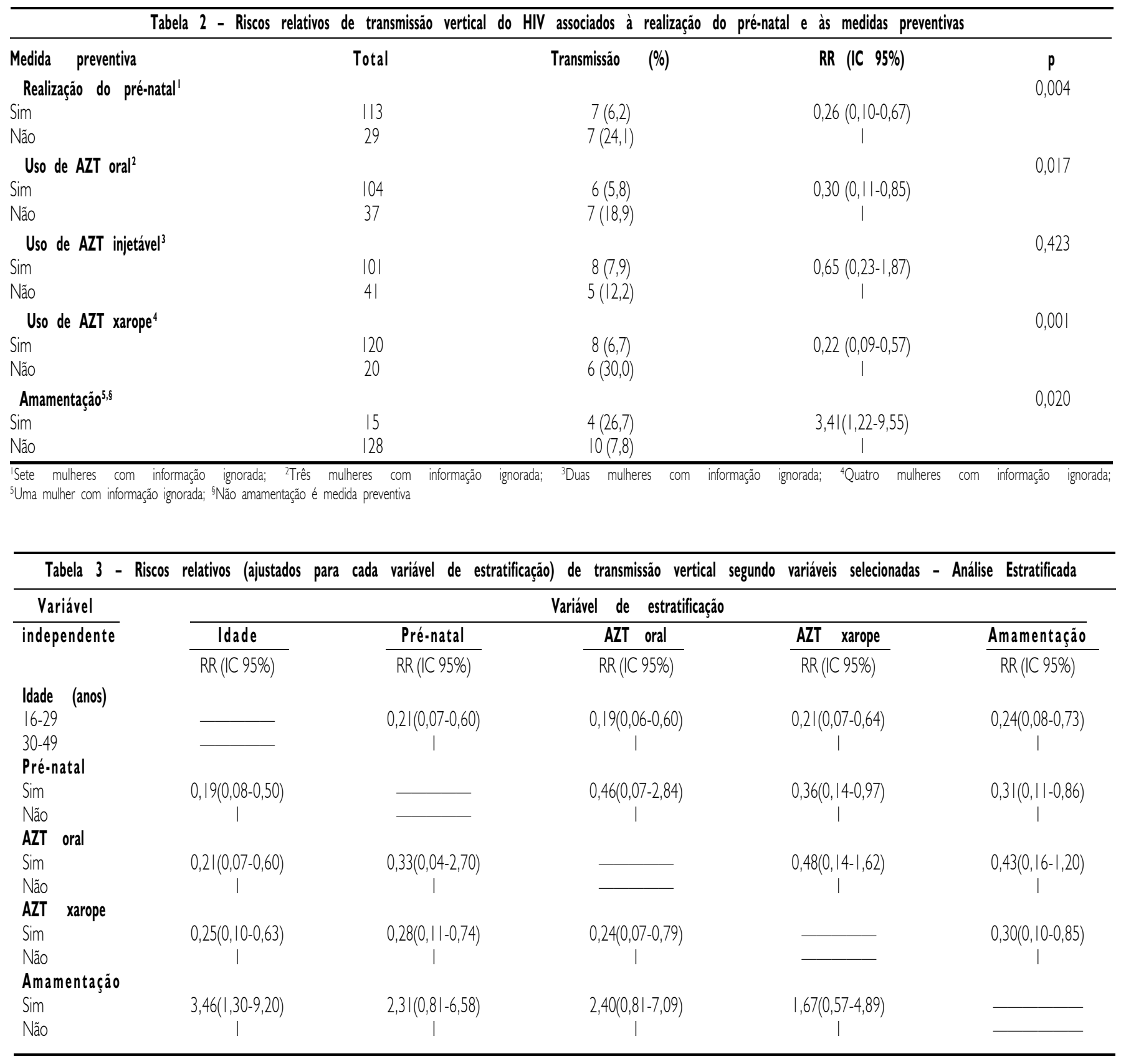

idades gestacionais não houve diferença estatisticamente significativa $(p=0,16)$.

Na Tabela I são mostrados os riscos relativos de transmissão materno-infantil do HIV segundo: idade e nível de escolaridade materna, paridade, tipo de parto, peso do recémnascido, idade gestacional (método de Capurro) e tempo de bolsa rota. Observou-se que a idade materna e a idade gestacional associaram-se à transmissão vertical do HIV de maneira estatisticamente significante.
A Tabela 2 mostra os riscos relativos de transmissão vertical do HIV associados à realização do pré-natal e às medidas preventivas preconizadas internacionalmente. Com exceção do uso de AZT injetável, em todas as outras medidas observou-se redução estatisticamente significante da transmissão.

$\mathrm{Na}$ análise univariada, o risco de transmissão materno-infantil do HIV esteve associado, de modo estatisticamente significante, a seis fatores: idade materna, realização de pré-natal, uso de AZT oral, uso de AZT xarope, idade gestacional (Capurro) e amamentação. Por meio de análise estratificada, esses resultados foram ajustados para cada uma das outras variáveis (exceção da variável: idade gestacional que não entrou na análise por apresentar muitas mulheres com informação ignorada). Os resultados obtidos aparecem na Tabela 3.

O menor risco de transmissão observado em mulheres mais jovens pouco se alterou 
após ajuste para cada um dos outros fatores. De modo análogo, os riscos de transmissão associados às variáveis selecionadas também não apresentaram grande variação após ajuste por idade.

De modo geral, a proteção quanto à transmissão materno-infantil, associada à realização do pré-natal, uso de AZT oral, uso de AZT xarope e desmame foi atenuada na análise estratificada (Tabela 3). O uso de AZT xarope foi o único fator que continuou associado de modo estatisticamente significante ao risco de transmissão após controlar por qualquer uma das outras variáveis.

A ocorrência de transmissão materno-infantil do HIV caiu de modo consistente durante os três anos do estudo (Qui-quadrado de tendência linear $=6,880, p=0,008)$. No primeiro ano a taxa foi $19,6 \%$, no segundo $7 \%$ e no terceiro igual a 3,6\%.

\section{Discussão}

O risco detransmissão materno-infantil do HIV foi igual a 0, I0 (IC 95\% 0,03-0, I6), valor este menor que o risco encontrado em estudo de coorte realizado no Brasil em quatro cidades do Estado de São Paulo, incluindo a cidade de Santos, 0, 16 (IC 95\% 0, 13-0,20), sem a utilização de qualquer medida preventiva ${ }^{23}$. A queda de $38 \%(0,16$ para 0,10$)$ ocorreu em grande parte devido à implantação das medidas de prevenção adotadas pelo programa municipal de DST/Aids do município.

Nos últimos anos, na maioria dos países desenvolvidos têm sido encontrados riscos entre 0,04 a $0,13^{13,14,24-27}$. Portanto, o resultado obtido neste trabalho $(0,10)$ pouco diferiu daqueles observados em países desenvolvidos.

Em novembro de 1997, em artigo publicado pelo Centers for Disease Control and Prevention, verificou-se um aumento dramático na testagem anti-HIV e uso de zidovudina (AZT) entre gestantes infectadas pelo HIV nos Estados Unidos, entre 1992 e 1996. A este aumento correspondeu um declínio de 43\% na incidência de Aids entre crianças que foram infectadas através da transmissão perinatal ${ }^{28}$.

A proteção quanto à transmissão vertical do HIV em mulheres mais jovens também foi encontrada no French Cohort Study ${ }^{6}$. Naquela investigação, o risco de infecção da criança aumentou com a idade materna (16\% para mulheres com menos de 25 anos e $30 \%$ para as com mais de 35 anos). Em outro estudo observacional, no Women and Infants Transmission Study, foi encontrado na análise univariada um $R R=1,5$ I (IC 95\% I,07 - 2, I3, $p=0,02$ ), para idade da gestante acima de 30 anos $^{29}$. Cabe ressaltar que, no presente estudo, a proteção observada em mulheres com menos de 30 anos pouco se alterou após ajuste por outras variáveis.

No European Collaborative Study, idade materna e raça não foram associados significantemente ao risco de transmissão ${ }^{25}$. No estudo de coorte realizado no Estado de São Paulo, os autores não encontraram associação significante entre a idade materna e o risco de infecção, porém as mulheres negras foram significantemente menos capazes de transmitir o HIV comparadas às mulheres brancas $(\mathrm{OR}=$ $0,3$; IC 95\% 0,I - 0,9, $p=0,04)^{23}$. Nível de escolaridade, grupo étnico e renda familiar materna não se associaram significantemente com o risco de transmissão materno-infantil do HIV, neste estudo.

Um dos principais fatores associados à transmissão perinatal do HIV é o tempo de bolsa rota $30,31,32$. Nesta pesquisa, ocorreu associação entre o maior tempo de bolsa rota (mais de 4 horas) e o risco de transmissão, porém não estatisticamente significante. $\mathrm{Da}$ mesma forma, a prematuridade (idade gestacional inferior a 38 semanas) e o menor peso do recém-nascido ao nascimento mostraram estar relacionados ao risco de infecção pelo vírus ${ }^{4,29,15}$. Neste estudo, apenas a idade gestacional inferior a 38 semanas mostrou associação significante $(p<0,05)$

As medidas de prevenção recomendadas pela Coordenação Nacional de DST/Aids ${ }^{18}$ pela sua eficácia comprovada são: o uso de AZT oral, injetável e xarope, realização de cesariana eletiva e não amamentação destas crianças.

Neste trabalho, o parto por via alta protegeu contra a transmissão do HIV, mas esta associação não foi estatisticamente significante. A realização de apenas duas $(1,4 \%)$ cesarianas eletivas tendo como indicação a sorologia materna positiva para o HIV pode ser justificada pelo fato de que somente a partir de março de 200 I foi adotado protocolo específico para realização de cesárea eletiva nas gestantes HIV soropositivas, segundo normas da Coordenação Nacional de DST/Aids' ${ }^{18}$. Nas cesarianas restantes não se soube se foram de emergência ou eletiva.

Das quatro medidas de prevenção efetivamente recomendadas no Brasil durante o período do estudo, a única que não mostrou associação estatisticamente significante com a transmissão vertical na análise univariada foi o uso de AZT injetável, provavelmente devido ao número pequeno de pares de mães/crianças.

$\mathrm{Na}$ análise univariada, o risco de transmissão vertical foi menor nas mulheres que haviam feito pré-natal. Como esperado, a realização de pré-natal e a adoção das medidas de prevenção estiveram associadas. A realização de pré-natal foi altamente protetora (RR=0,26; IC 95\% 0, I0 - 0,26) contra a transmissão vertical do HIV. No pré-natal, a gestante soropositiva para o HIV tem informação e acesso a medidas preventivas contra a transmissão maternoinfantil do vírus. Este fato explica a perda de significância estatística ao se ajustar por algumas medidas de prevenção (tipo de aleitamento; uso de AZT oral).

Das 7 I gestantes que descobriram sua condição de infecção pelo HIV durante 0 pré-natal, 59 (83\%) fizeram uso de AZT oral, mostrando claramente a associação descrita. As restantes, que desconheciam a sua sorologia, não tomaram AZT porque o diagnóstico laboratorial foi muito próximo do parto, não havendo tempo para a administração da droga.

$\mathrm{Na}$ análise estratificada, o uso de AZT xarope foi a única medida preventiva que continuou associada de modo independente com a redução de transmissão vertical.

Estudos realizados na Europa e EUA confirmaram o benefício de usar o AZT na redução da transmissão materno-infantil do HIV ${ }^{4}, 26$, até mesmo quando a ação preventiva for realizada mais tardiamente: final da gravidez ou no parto e quando realizada após o parto, para o recém-nascido, nas primeiras 48 horas de vida ${ }^{14,15,16,33}$.

A queda do risco de transmissão entre os anos de seguimento pode ser devida a um aumento na adoção de medidas de prevenção pelo Programa Municipal de DST/Aids.

O estudo aponta também para a importância de realização de todas as medidas preventivas, com o que se poderá conseguir reduções ainda mais significativas. 
Para reduzir a transmissão vertical do HIV, os requisitos importantes para a implementação de ações em nosso meio incluem: acesso e utilização de serviços de saúde para o período pré-natal, intraparto e pós-parto com profissionais de saúde adequadamente treinados; serviços de aconselhamento pré e pós-teste; oferecimento de testes de HIV confiáveis e sem custo; laboratório equipado e apropriado para monitorar parâmetros sangüíneos relacionados à infecção pelo HIV.

O estudo permitiu concluir pela importância das medidas de prevenção e pela necessidade de estimular as ações que visam a detecção precoce de gestantes infectadas pelo HIV e sua captação o mais cedo possível para início do pré-natal e início das intervenções disponíveis. A vigilância destes casos, ou seja, a ampliação do oferecimento universal do teste anti-HIV no pré-natal e o aumento de cobertura de todas as ações que visam a prevenção da transmissão do HIV irão reduzir ainda mais os riscos de transmissão materno-infantil no nosso País.

\section{Conflito de interesse: não há.}

\section{SUMMARY

$\begin{array}{llcrrr}\text { Mother-TO-CHILD } & \text { TRANSMISSION } & \text { OF } \\ \text { HUMAN IMMUNODEFICIENCY } & \text { VIRUS } & & \text { (HIV-I): } \\ \text { EVALUATION OF CONTROL } & \text { MEASURES IN } & \text { THE } \\ \text { CITY OF SANTOS } & & & \end{array}$

O BIECTNES. To estimate the risk of mother-tochild transmission (MTCT) ofHIV-I and evaluate the effect of preventive methods on vertical transmission of HIV, such as: use of AZT by pregnant women during the prenatal period, labor and delivery; use of AZT in newborns; replacement of breastfeeding by formula; and indication of cesarean section.

METHOds. This was a cohortstudy. Datawas collected from medical records of pregnant women and of children followed at reference health centers for HIVIAIDS patients. To estimate the risk ofMTCT we divided the number of mothers whose children acquired the virus through vertical transmission by the total number of mothers included in the study; the relative risks were calculated with a $\mathrm{Cl}=95 \%$. O ccurrence of transmission was regarded as a dependent variable, the otherfactors (maternal age, use of oral AZT and use of AZT syrup, gestational age and breastfeeding) were considered as independent variables. Mantel-
Haenszel's techniqueswere used in this analysis to control the possible effect of some variables.

RESULTS. The occurrence ofHIV inMTCT was identified in 144 children. Fourteen were classified as infected. Risk oftransmission was of 0.097 (95\% Cl; 0.030-0. 1 63). The risk of HIV vertical transmission was smaller in women under thirty years of age when compared with olderones. In the univariate analysis, the MTCT risk was significantly asso ciated with maternal age, prenatal care, use of oral AZT and use of AZT syrup, gestational age and breastfeeding.

CONCLUSION. This study showed that the implementation of preventive measures is important in the prevention of mother-to-child transmission of HIV, providing a risk reduction of almost $40 \%$ when compared to that before use of these preventive measures. [RevAssoc Med Bras 2005; $5 \mathrm{I}(\mathrm{I}): 54-60]$

KEY WORDS: Mother-to-child or vertical transmission. HIV. Acquired immunodeficiency syndrome. Risk factors. Protective measures.

\section{ReferênCIAS}

I. Rates of mother-to-child transmission of HIV-I in Africa, America and Europe: results from 13 perinatal studies. The Working Group on Mother-to-child Transmission of HIV. J Acquir Immune Defic Syndr Hum Retrovirol 1995;8:506- 10.

2. Pizzo PA, Wilfert CM. Pediatric AIDS: the challenge of HIV infection in infants, children, and adolescents. In: editors. Perinatally acquired HIV infection. Baltimore: Williams \& Wilkins; 1991. p.3-21.

3. Burns DN, Landesman S, Muenz LR, Nugent RP, Goedert J], Minkoff $H$, et al. Cigarette smoking, premature rupture of membranes, and vertical transmission of HIV-I among women with low $\mathrm{CD}_{4}+$ levels. I Acquir Immune Defic Syndr Hum Retrovirol 1994,7:7| 8-26.

4. European Collaborative Study. Risk factors for mother-to-child transmission of HIV-I. Lancet 1992;339: 1007-12.

5. Garcia PM, Kalish LA, Pitt J, Minkoff H, Quinn TC, Burchett SK, et al. Maternal levels of plasma human immunodeficiency virus type- I RNA and the risk of perinatal transmission. $\mathrm{N}$ Engl J Med 1999;341:394-402.

6. Mayaux M-J, Blanche S, Rouzioux C, Le Chenadec J, Chambrin V, Fertion G, et al. Maternal factors associated with perinatal HIV-I transmission: the french cohort study: 7 years of follow-up observation. I Acquir Immune Defic Syndr Hum Retrovirol 1995;8: 188-94.

7. Miotti PG, Taha TE, Kumwenda NL, Broadhead R, Mtimavalye LA, Van der Hoeven
L, et al. HIV transmission through breastfeeding: a study in Malawi. JAMA 1999; 282:744-9.

8. Mofenson LM, Harris DR, Rich K, Meyer WA $3^{\text {rd }}$, Read JS, Moye J Jr, et al. Serum HIV-I p24 antibody, HIV-I RNA copy number and CD4 lymphocyte percentage are independently associated with risk of mortality in HIV-Iinfected children. National Institute of Child Health and Human Development Intravenous Immunoglobulin Clinical Trial Study Group. AIDS 1999; 13:31-9.

9. Newell ML, Gray G, Bryson Y. Prevention of mother-to-child transmission of HIV-I infection. AIDS 1997; I I:S 165-S72.

10. Stiehm M. Newborn factors in maternal-infant transmission of pediatric HIV infection. J Nutr 1996; | 26: | 632S-6S.

I I.Taha TE, Gray RH, Kumwenda NI, Hoover DR, Mtimavavalye LA, Liomba GN, et al. HIV infection and disturbances of vaginal flora during pregnancy. J Acquir Immune Defic Syndr Hum Retrovirol 1999;20:522-9.

12. European mode of delivery collaboration. elective caesarean-section versus vaginal delivery in prevention of vertical HIV-I transmission: a randomised clinical trial. Lancet 1999;353: 1035-9.

13.Connor EM, Sperling RS, Gelber R, Kiselev P, Scott G, O'Sullivan MJ, et al. For The Pediatric AIDS Clinical Trials Group Protocol 076 Study Group. N Engl J Med 1994; 331: | 173-80.

14. Wade NA, Birkhead GS, Warren BL, Charbonneaux TT, French PT, Wang L, et al. Abbreviated regimens transmission of the human immunodeficiency virus. N Engl J Med | 998;339: | 409- | 4 .

15. Shaffer N, Roongpisuthipong A., Siriwasin W, Chotpitayasuthipong T, Chearskul N, Nancy N, et al. Maternal virus load perinatal human immunodeficiency virus type I subtype $E$ transmission. Thai J Infect Dis 1999; 179:590-9.

16. Fiscus SA, Adimora AA, Schoenbach VJ, McKinney R, Lim W, Rupar D, et al. Trends in human immunodeficiency virus (HIV) counseling, testing, and antiretroviral treatment of HIVinfected women and perinatal transmission in North Carolina. J Infect Dis 1999; | 80:99-105.

17. Ministério da Saúde. Boletim Epidemiológico Aids 2002;16(1). 01-14 a 52 Semanas Epidemiológicas, abril a dezembro de 2002.

18. Brasília. Ministério da Saúde. Recomendações para profilaxia da transmissão materno-infantil do HIV e terapia anti-retroviral. 2004. Disponível em: http://www.aids.gov.br/final/ b i bliotecalgestante_2004/ ConsensoGestante2004.doc.

19. Ministério da Saúde. Guia de tratamento clínico da infecção pelo HIV em crianças. Brasília (DF); 2001 . (Série a Normas e Manuais Técnicos, n. 134).

20. Armitage P, Berry G. Statistical methods in medical research. Oxford: Blackwell Scientific Publications; 1997.

21. Kirkwood BR. Essentials of medical statistics. Oxford: Blackwell Scientific Publications; 1998. 
22. Rothman KG, Greenland S. Precision and validity in epidemiologic studies. In: Rothman KG, Greenland S, editors. Modern epidemiology, $2^{\text {nd }}$ ed. Philadelphia: LippincottRaven; 1998. p.II5-34.

23. Tess B, Rodrigues L, Newell ML, Dunn D, Lago T, the São Paulo Collaborative Study for Vertical Transmission of HIV-I. Breastfeeding, genetic, obstetric and other risk factors associated with mother-to-child transmission of HIV-I in Sao Paulo State, Brazil. AIDS, 1998; | 2:513-20.

24. Sperling R, Shapiro D, Coombs R, Todd J, Herman S, McSherry G, et al. Maternal viral load, ZDV treatment, and the risk of transmission of human immunodeficiency virus type I from mother to infant. $N$ Engl J Med 1996;335:1621-9.

25. European Collaborative Study. Vertical transmission of HIV-I: maternal immune status and obstetrics factors. AIDS 1996; |0:1675-8|.
26. Newell ML, Thorne C. Pregnancy and HIV infection in Europe. Acta Paediatr Suppl 1997;421:10-4.

27. Mandelbrot L, Chenadec J, Berrebi A, Bongain A, Benifla JL, Delfraissy J-F, et al. French Perinatal Cohort. Perinatal HIV-I transmission: interaction between Zidovudine prophylaxis and mode of delivery. JAMA 1998;280:55-60.

28. Centers for Disease Control and Prevention. Update: perinatally acquired HIV/AIDSUnited States. MMWR Morb Mortal Wkly Rep 1997;46: 1087-95.

29. Landesman SH, Kalish LA, Burns DN, Minkoff $\mathrm{H}$, Fox HE, Zorrilla C, et al. Obstetrical factors and the transmission of human immunodeficiency virus type I from mother to child. N Engl J Med 1996;334:1617-23.

30. European Collaborative Study. Perinatal findings in children born to HIV-infected mothers. $\mathrm{Br} J$ Obstet Gynaecol 1994; 94:815-9.
31. Minkoff $H$, Mofenson LM. The role of obstetric interventions in the prevention of pediatric human immunodeficiency virus infection. Am J Obstet Gynecol 1994;171: I 167-75.

32. Mandelbrot L, Mayaux M-J, Borgain A, Berrebi A, Moudoub-Jeanpetit $Y$, Benilla J-L, et al. Obstetric factors and mother-to-child transmission of human immunodeficiency virus type I: French perinatal cohorts. Am J Obstet Gynecol 1996; 175:661-7.

33. Lallement M, Jourdain G, Le Coeurs, Kim S, Koetsawang S, Comeau AM, et al. A trial of shortened zidovudine regimens to prevent mother-to-child transmission of human immunodeficiency virus type I. N Engl J Med 2000;343:982-91.

Artigo recebido: 08// 2/2003 Aceito para publicação: 26/04/2004

\section{www.ramb.org.br}

A Ramb disponibiliza agora um novo serviço para os nossos colaboradores:

0 envio de artigos pela internet. Através do nosso publicador, que agiliza o fluxo de submissão com mais rapidez e versatilidade, você poderá enviar seu artigo para publicação na Ramb. Experimente: é muito mais cômodo, muito mais rápido e você ainda poderá acompanhar on line o curso de sua apreciação. Acesse www.ramb.org.br 